\section{Changes in suicide in England and Wales, 1960-1997}

\author{
G. M. G. MCCLURE
}

\section{Background Methods of suicide and} suicide rates in England and Wales have fluctuated considerably since the 1960s.

\begin{abstract}
Aims To review the changes that have occurred in suicide rates in England and Wales between 1960 and 1997.
\end{abstract}

Method Suicide rates, derived from total annual suicides and the estimated annual resident population, were obtained from the Office for National Statistics.

Results Suicide rates decreased in both genders between the early 1960s and the increased between 1975 and 1990, while the rate for females continued to fall. Between 1990 and 1997, the rate decreased for males and females in all age groups, particularly for those using motor vehicle exhaust gas; the latter finding is associated with increasing use of cataly tic converters.

Conclusions Following the increase in suicide among males until 1990 there was a decrease for both genders between 1990 and 1997, consistent with the 'Health of the Nation' target.

\section{Declaration of interest National} Health Service funding for honorary senior lecturer sessions with Imperial College. mid-1970s. The rate for males then
The suicide rate for both genders reached a post-war peak in the early 1960 s. Rates then declined steadily in both genders between 1963 and 1975. The overall decrease in suicide rate was associated with a decrease in poisoning by domestic gas, which was being detoxified at this time. McClure (1984) reported a reversal of the decline in rates between 1975 and 1980, and demonstrated that this was not due to changes in the recording of 'undetermined' deaths or 'accidental deaths' by causes similar to suicide. The continuing increase in suicide rates for males of all ages in England and Wales was due principally to an increase in the 25- to 54-year age group (McClure, 1987). Kelley \& Bunting (1998) noted a decrease in suicide rate in England and Wales between 1991 and 1996, which was related to a decrease in the proportion of suicides attributed to poisoning with motor vehicle exhaust gas.

\section{METHOD}

The number of annual suicides, defined according to categories E950-E959 of ICD10 in England and Wales over the period 1960-1997 (World Health Organization, 1992), were obtained from the Registrar
General's Office (1960-1973), the Office of Population Censuses and Surveys (1974-1990) and the Office for National Statistics (1991-1997). Suicide rates were calculated from the estimated resident population, which from 1990 onwards was based on the 1991 census. As suicides may be mis-attributed, rates of 'undetermined' deaths in categories comparable to suicide (E980-E989) were also obtained. Changes in rates of suicide by different methods and in different age groups were examined during this period. Particular attention was paid to the period 1990-1997 in relation to the 'Health of the Nation' target of reducing the suicide rate by at least $15 \%$ between 1990 and 2000 (Royal College of Psychiatrists, 1992; Secretary of State for Health, 1992).

\section{RESULTS}

Suicide rates for all ages of both genders between 1960 and 1997 are displayed in Fig. 1.

\section{Changes in suicide rates in males}

The suicide rate for males declined from 145 per million in 1963 to 91 per million in 1975 . It then rose to 120 per million by 1990 , representing an increase of $32 \%$ between 1975 and 1990. During this period the 'undetermined' death rate for males rose by $74 \%$, indicating that the increase in suicide rate between 1975 and 1990 was a real increase and was not due to mis-classification of suicides into the 'undetermined' category.

The rate for males then decreased from 120 per million in 1990 to 103 per million in 1997 , a decrease of $14 \%$, which is

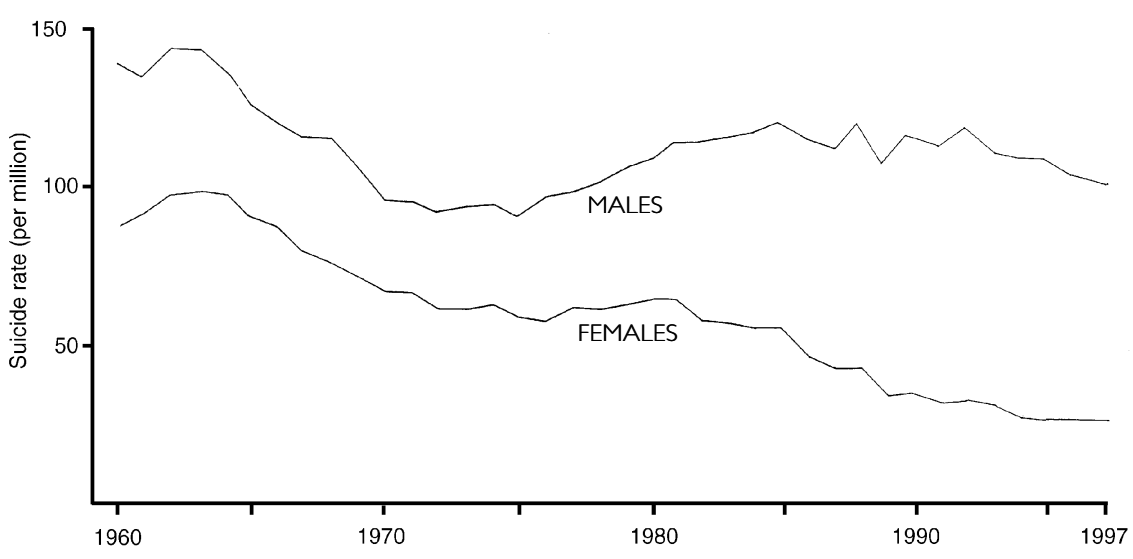

Fig. I Suicide rate for all ages 1960-1997 in England and Wales. 


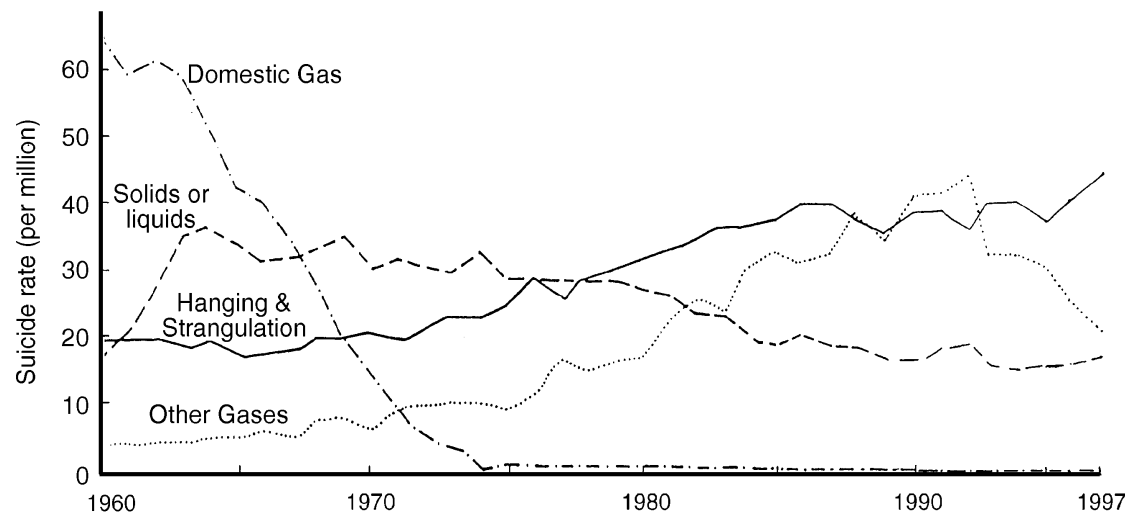

Fig. 2 Rates of suicide by different methods 1960-1997 in England and Wales - males.

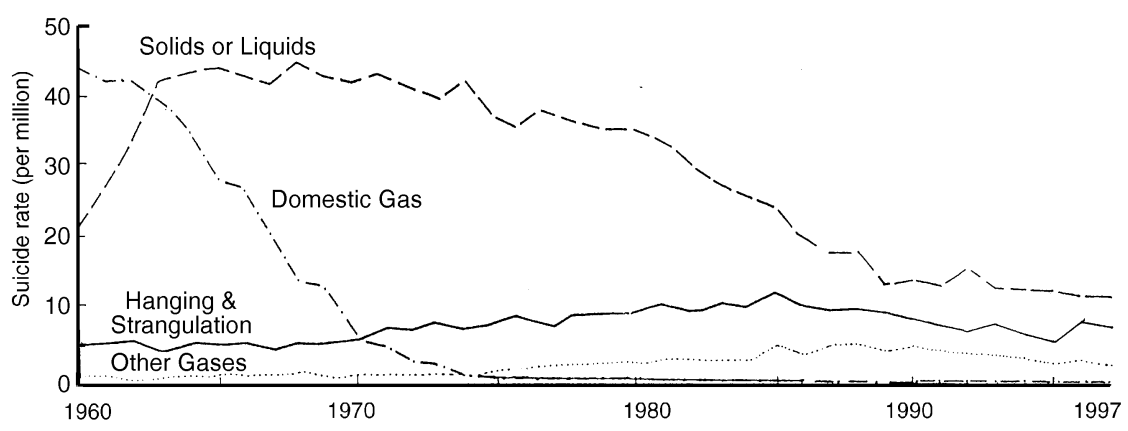

Fig. 3 Rates of suicide by different methods 1960-1977 in England and Wales - females.

within the 'Health of the Nation' target. The combined total of male suicides and 'undetermined' deaths decreased by $11 \%$ between 1990 and 1997, indicating that there has been a real decrease in male suicide during this period.

\section{Changes in suicide rates in females}

The suicide rate for females decreased from 99 per million in 1963 to 60 per million in 1975. The rate for females then continued to decline to 37 per million in 1990, a decrease of $38 \%$ between 1975 and 1990. The combined total of suicide and 'undetermined' deaths between 1975 and 1990 decreased by $27 \%$, indicating a real decrease in female suicide during this period.

The suicide rate for females decreased from 37 per million in 1990 to 29 per million in 1997 , a decrease of $22 \%$. This is well within the 'Health of the Nation' target. The 'undetermined' rate for females decreased by $15 \%$ between 1990 and 1997, confirming that the recorded decline in suicide rate indicates a real decline in suicides during this period.

\section{Changes in methods for males}

As shown in Fig. 2, the rate of male suicide by poisoning with solid and liquid substances has gradually declined since the mid 1960s, decreasing by $43 \%$ between 1975 and 1990. During the same period, rates of male suicide by hanging and strangulation increased by $48 \%$. The male suicide rate for poisoning with gases other than domestic gas increased substantially - by $330 \%$ - between 1975 and 1990 , by which time it was the most popular single method of suicide in males.

Between 1990 and 1997, the rate of male poisoning by solids and liquids levelled off, whereas suicide by hanging and strangulation continued to increase (by 22\%). Between 1990 and 1997 there was a substantial decrease in poisoning by other gases and vapours (E952) - from 43 per million in 1990 to 22 per million in 1997 , a decrease of $49 \%$. For motor vehicle exhaust gas alone (E952.0) the rate decreased from 41 per million in males in 1990 to 16 per million in 1997, a decrease of $61 \%$. Considering 'undetermined' poisoning by motor vehicle exhaust gas alone (E982.0), the decrease was $74 \%$ during the same period, indicating that the recorded drop in suicide rate by this method represented a real decrease in suicide.

\section{Changes in methods for females}

As shown in Fig. 3, the rate of female suicide by poisoning with solids and liquids decreased from 38 per million in 1975 to 16 per million in 1990, a decrease of $58 \%$. During the same period, there was an increase in poisoning with gases other than domestic gas of $380 \%$. Suicide by hanging and strangulation increased between the 1960s and the mid-1970s, and then decreased by 3\% between 1975 and 1990.

Female poisoning by solid or liquid substances continued to decrease (by $22 \%$ ) between 1990 and 1997. There was no change in rates of hanging, strangulation and suffocation. The rate of female suicide by poisoning with other gases and vapours (E952) decreased by $41 \%$. For motor vehicle exhaust gas alone (E952.0), the rate decreased by $60 \%$ between 1990 and 1997 . Considering 'undetermined' poisoning by motor vehicle exhaust gas alone (E982.0), the decrease was $63 \%$ between 1990 and 1997 , indicating that the recorded decrease in suicide by this method represents a real decrease in suicide.

\section{Suicide rates in different age groups in males}

Figure 4 shows the changes in the rate of male suicide in different age bands. As the characteristics of child suicides differ from those of adult suicides (McClure, 1994), children under the age of 15 years have been excluded. There was a decrease in the rate of male suicide in all age bands between the early 1960s and the mid-1970s. Between 1975 and 1990 there was a gradual increase in suicide rate, particularly in the 15- to 44-year age group. Between 1990 and 1997 there was then a decrease in suicide rate for males of all age groups. This decrease was most pronounced at $19 \%$, in the 35 - to 44 -year age group. The decrease in rate was less pronounced in the 25- to 34-year age group; accordingly, this group now has the highest rate of suicide in males. 


\section{Suicide rates in different age groups in females}

Figure 5 shows that for females the rate for all age groups declined between the early 1960s and the mid-1970s. There was a much less pronounced increase in the rate in the late 1970s, and a subsequent decline in all age bands between 1975 and 1990. There was a further decrease for females in all age bands between 1990 and 1997.

\section{DISCUSSION}

Suicide causation is multi-factorial, with complex and sometimes indirect interaction of factors (McClure, 1999).

\section{Changes in method of suicide}

The decrease in suicide rate between 1963 and 1975, in both genders, was due principally to a decrease in the availability of poisonous domestic gas and barbiturates. Subsequently, the switch from overdosing (which has moderate lethality) to poisoning with vehicle exhaust gas and hanging and strangulation (which have high lethality) may partly explain the increase in male suicide rate between 1975 and 1990. Car ownership increased by approximately $45 \%$ in this period (Government Statistical Service, 1993), particularly among young males. The increase of over $300 \%$ in both genders in poisoning by motor vehicle exhaust gas, however, greatly exceeded the increase in availability of motor cars, indicating the effect of widespread reporting of its potential as a method of suicide.

Between 1990 and 1997 the reduction in the male suicide rate may be accounted for by the reduction in poisoning by motor vehicle exhaust gas, whereas only a proportion of the reduction in the female rate can be accounted for by this factor. Kendell (1998) reported that all petrolpowered cars sold in the UK since 31 December 1992 have had to have catalytic converters, which decrease the carbon monoxide content of motor vehicle exhaust gas. As only $36 \%$ of cars had catalytic converters by 1997, however, this cannot account for the observed decrease

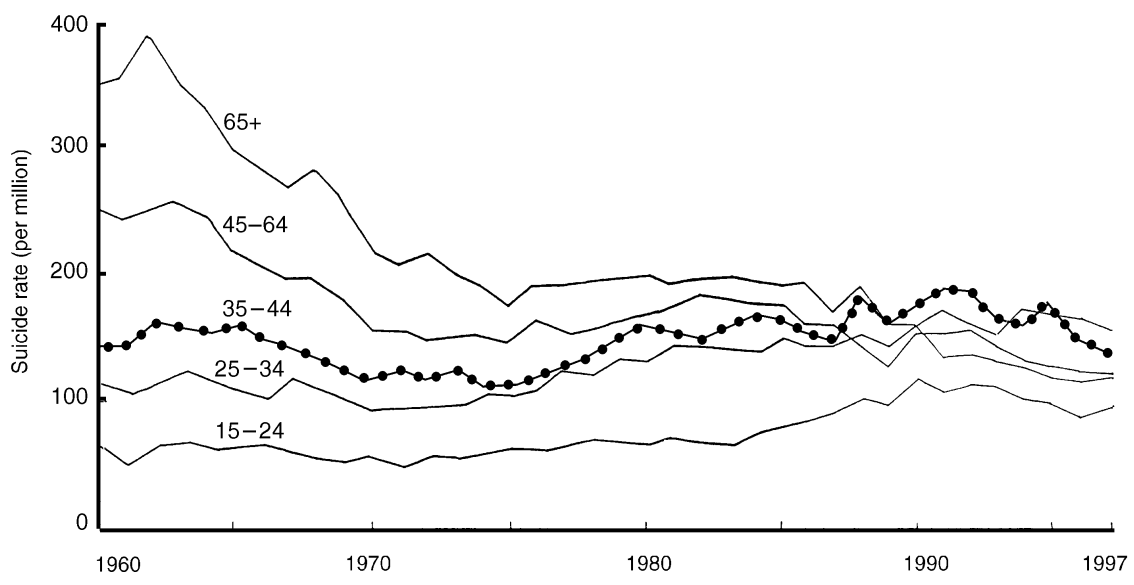

Fig. 4 Suicide rates in different age groups 1960-1997 in England and Wales - males.

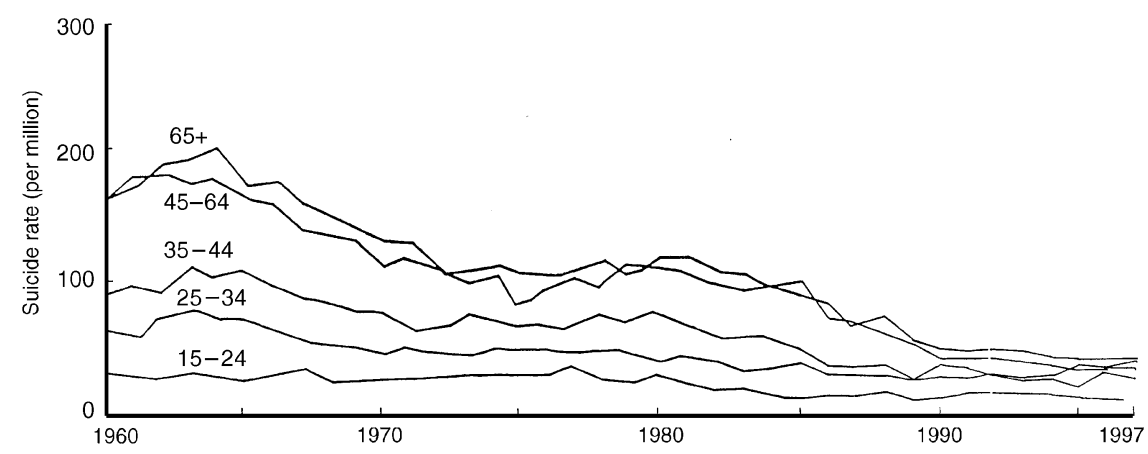

Fig. 5 Suicide rates in different age groups 1960-1997 in England and Wales - females.

in rates of suicide by this method $-61 \%$ in males and $60 \%$ in females - between 1990 and 1997. It is therefore likely that there has been an independent decrease in suicide by poisoning involving vehicles without catalytic converters.

\section{Psychosocial stress}

Between 1975 and 1990 there were increases in male unemployment and violence (Government Statistical Service, 1993), both of which are related to suicide (Dooley, 1990; Pritchard, 1992). Evidence of increasing anomie between 1975 and 1990 included increases in the number of single-person households and the numbers of divorced males who had not re-married (Government Statistical Service, 1993). The number of warrants issued for repossession of properties through default of payment resulting from debt increased in this period, as did the numbers of people defined as homeless (Government Statistical Service, 1993).

Substance misuse and alcohol consumption, which have been shown to be associated with suicide rate, increased between 1975 and 1990 (Government Statistical Service, 1993). HIV infection, which had until then particularly affected young male homosexuals, might also have contributed to the increase in suicide rate in young males up to 1990 .

Women became more independent between 1975 and 1990, as demonstrated by the increase in numbers of economically active married women, the doubling of the prevalence of lone-mother families from $9 \%$ to $18 \%$ during the same period, and the delayed age of marriage of women (Government Statistical Service, 1993). The systemic interaction of this change in the role of women, with possible negative consequences upon the mental health of young men, deserves further investigation.

\section{Suicide prevention}

As catalytic converters cannot entirely explain the decrease in suicide rate in both genders between 1990 and 1997, it is possible that psychosocial stress has decreased during this period. The national economy and unemployment levels improved substantially between 1990 and 1997 (Office for National Statistics, 1999).

There is also a possibility that improvements in services for suicide prevention 
contributed to the reduction in suicide rates for both genders between 1990 and 1997, but particularly for females and the elderly. The Royal College of Psychiatrists became more proactive, undertaking suicide prevention and 'Defeat Depression' campaigns. 'Care in the community' was developed, with increasing awareness of risk assessment in relation to suicide.

\section{'Health of the Nation' target for suicide reduction}

The improvement in suicide rates in line with the 'Health of the Nation' target between 1990 and 1997 is encouraging. It should not lead to complacency, however, as the recent increase among males in rates of suicide by hanging, strangulation and suffocation is of concern, because the availability of these methods cannot easily be controlled. Methods of reducing the suicide rate based on a greater understanding of causal factors must be developed, because any reduction in suicide rate caused by a reduction in the lethality of vehicle exhaust gas is likely to be temporary.

\section{REFERENCES}

Dooley, E. (1990) Prison suicide in England and Wales, 1972-87. British Journal of Psychiatry, I56, 40-45.

Government Statistical Service (1993) Social Trends. London: HMSO

Kelly, S. \& Bunting, J. (1998) Trends in suicide in England and Wales, 1982-96. Population Trends, 92 $29-41$.

Kendell, R. E. (1998) Catalytic converters and prevention of suicide. Lancet, 352, 1525.

McClure, G. M. G. (1984) Trends in suicide rate for England and Wales, 1975-80. British Journal of Psychiatry, 144, 119-126.

— (1987) Suicide in England and Wales, 1975-1984. British Journal of Psychiatry, 150, 309-314.

\section{CLINICAL IMPLICATIONS}

- Availability of lethal agents, particularly motor vehicle exhaust gas, may affect suicide statistics.

- Young males remain the group at the highest risk for suicide, whereas the rate for females has steadily declined.

Suicide reduction between 1990 and 1997 was within the 'Health of the Nation' target of a reduction of $15 \%$ between 1990 and 2000 .

\section{LIMITATIONS}

Mortality statistics may incorrectly attribute some deaths to suicide.

- Suicide rates are based on census estimates of the resident population.

- Causal explanations are complex and multi-factorial.

G. M. G. McCLURE, FRCPsych, Imperial College School of Medicine, Chelsea and Westminster Hospital, 369 Fulham Road, London SWI0 9NH

(First received 25 January 1999, final revision 16 June 1999, accepted 16 June 1999)

_ (1994) Suicide in children and adolescents in England and Wales, 1960-1990. British journal of Psychiatry, 165, 510-514.

- (1999) An integrative systems model. In Family Matters: Interfaces between Child and Adult Mental Health (eds P. Reder, M. McClure \& T. Jolley). London: Routledge, in press.

Office for National Statistics (1991-1997) Mortality Statistics: Cause. London: HMSO.

— (1999) Social Trends. London: Stationery Office. Office of Population Censuses and Surveys (19741990) Mortality Statistics: Cause. London: HMSO

Pritchard, C. (1992) Is there a link between suicide in young men and unemployment? A comparison of the UK with other European Community countries. British Journal of Psychiatry, 160, 750-756.
Registrar General's Office (1960-1973) Registrar General's Statistical Review for England and Wales: Part I: Tables (Medical). London: HMSO.

Royal College of Psychiatrists (1992) Mental Health of the Nation. The Contribution of Psychiatry. A Report of the President's Working Group. Council Report CRI6. London: Royal College of Psychiatrists.

Secretary of State for Health (1992) The Health of the Nation: A Strategy for Health in England. London: HMSO

World Health Organization (1992) International Classification of Diseases and Related Health Problems, Tenth Revision (ICD-10). Geneva: WHO. 